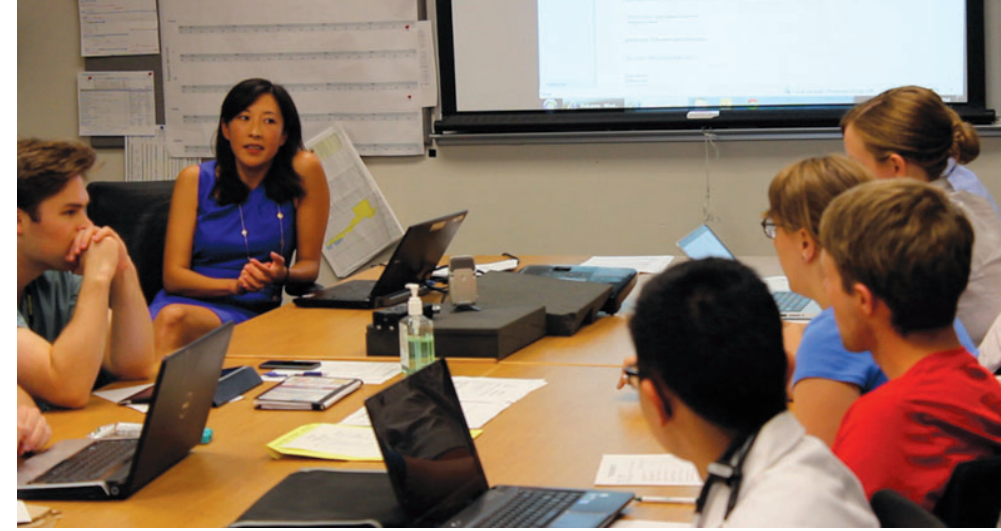

\title{
The flipped classroom for medical students
}

\section{Helen Morgan ${ }^{1}$, Karen McLean ${ }^{2}$, Chris Chapman ${ }^{3}$, James Fitzgerald ${ }^{4}$, Aisha Yousuf ${ }^{5}$ and Maya Hammoud ${ }^{1}$}

${ }^{1}$ Departments of Obstetrics and Gynecology and Learning Health Sciences, University of Michigan Medical School, Ann Arbor, Michigan, USA 2Division of Gynecologic Oncology, Department of Obstetrics and Gynecology, University of Michigan Medical School, Ann Arbor, Michigan, USA

${ }^{3}$ Instructional Design \& Technology Team, University of Michigan Medical School, Ann Arbor, Michigan, USA

4Department of Learning Health Science, University of Michigan Medical School, Ann Arbor, Michigan, USA

${ }^{5}$ Department of Obstetrics \& Gynecology, Sidra Medical and Research Centre, Doha, Qatar

\section{SUMMARY}

Background: The objectives of this curricular innovation project were to implement a flipped classroom curriculum for the gynaecologic oncology topics of the obstetrics and gynaecology medical student clerkship, and to evaluate student satisfaction with the change.

Methods: Four short online videos on the topics of endometrial hyperplasia, cervical dysplasia, evaluation of an adnexal mass, and ovarian cancer were created, and students were instructed to view them prior to a class-time active learning session. The Learning Activity Management System (LAMS) open-source online platform was used to create an active learning class-time activity that consisted of a coached discussion of cases. Student satisfaction with the two aspects of the flipped curriculum was obtained. In addition, lecture assessment for the gynaecologic oncology topics and aggregate student performance on the gynaecological oncology questions of the US National Board of Medical Examiners (NBME) Subject Examination were compared before and after implementation of the curriculum.

Results: Eighty-nine students rotated on the clerkship during the pilot period of analysis. Seventy-one students $(80 \%)$ viewed the videos prior to the class session, and 84 (94\%) attended the session. Student satisfaction was very high for both parts of the curriculum. There was no significant difference in aggregate student performance on the gynaecological oncology questions of the NBME Subject Examination.

Discussion: Our implementation of the flipped classroom curriculum for the gynaecologic oncology topics successfully demonstrates a promising platform for using technology to make better use of our students' time, and for increasing their satisfaction with the necessary didactic learning of the clerkship.
The flipped

classroom curriculum demonstrates a promising platform for using technology to make better use of students' time 
Teaching

approaches that

employ active

learning have

been shown to

create positive

learning

outcomes

\section{INTRODUCTION}

T he gynaecologic oncology topics of the obstetrics and gynaecology clerkship include the pathologies of endometrial, cervical, and ovarian neoplasms. Previously, each neoplastic process was taught during three 1-hour didactic lectures. In an effort to improve the educational experience for third-year medical students on the clerkship, a flipped classroom curricular model was implemented in order to decrease the amount of required didactic time, and to increase student satisfaction with the didactic component of the clerkship.

In the general structure of a flipped classroom model, the learner is assigned content to review prior to the teaching session. Class time is used for the application of knowledge in an active learning session. ${ }^{1}$ Teaching approaches that employ active learning have been shown to create positive learning outcomes. $^{2}$ The flipped classroom model has been described as particularly well suited for medical education, as the pre-class assignment can create a framework of core knowledge, and the active learning exercise can then embed the knowledge in an interactive, compelling and engaging format. ${ }^{3}$ Some health profession schools are beginning to use the flipped classroom curricular model: graduate students in physiology scored higher on multiple-choice assessments after implementation of the flipped classroom model compared with traditional didactics. ${ }^{4}$ Nursing students randomised to a flipped classroom teaching model also scored higher on knowledge assessments; however, student satisfaction was lower with the flipped classroom model than with traditional lectures. ${ }^{5}$

The primary objectives of this curricular innovation project were

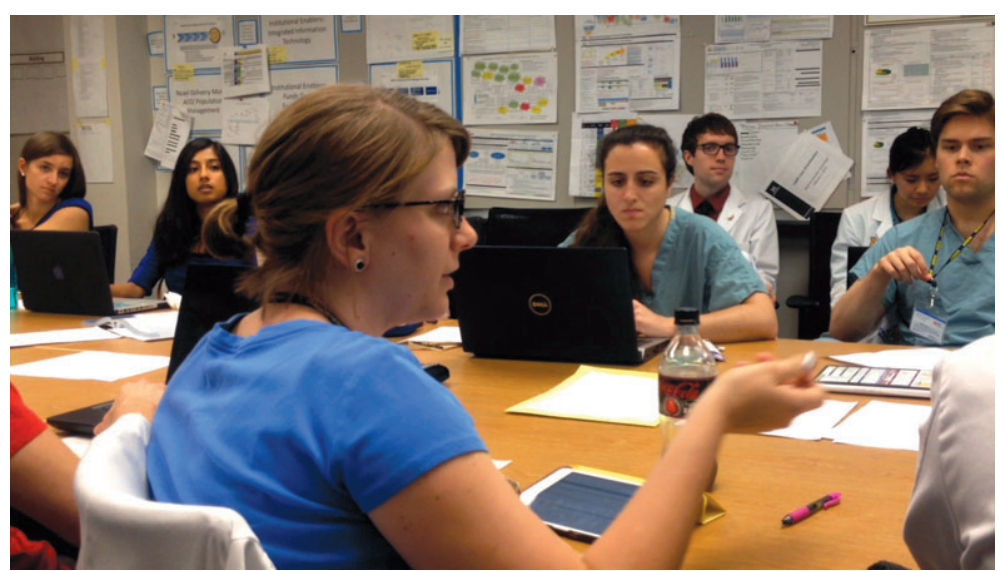

to implement a flipped classroom for the gynaecologic oncology topics, and to evaluate student satisfaction with the change. A secondary objective was to determine whether there was a change in student performance on the gynaecologic oncology topics of the National Board of Medical Examiners (NBME) Obstetrics and Gynaecology Subject Examination.

\section{METHODS}

\section{Pre-class assignment}

Four short videos were created, each less than 10 minutes in length, on the core gynaecologic oncology topics of cervical dysplasia, endometrial hyperplasia, evaluation of an adnexal mass and ovarian cancer. These videos contained a combination of annotated drawings, videos from gynaecological procedures and narrated PowerPoint slides. Students logged on to a password-protected online site to view the videos prior to the gynaecologic oncology session.

\section{Class-time activity}

We used the open-source design site Learning Activity Management System (LAMS) for the 1-hour case-based discussion that replaced the previous 3 hours of didactic lectures. ${ }^{6}$ LAMS 2.4 is a free software application that allows instructors to create case-based sessions for group teaching. All medical students at our institution are required to own a laptop computer, so access was not a barrier. Four cases were created for the learning session, with each case beginning with a patient's presentation for care. In class, students replied individually, on laptops and tablet devices, to short-answer prompts on the differential diagnoses, laboratory evaluation and management of each case. Collective responses were then projected anonymously, and faculty members used these answers to guide the subsequent discussion. Figure 1 illustrates the initial screenshot of the short-question prompt and the collective projected answers of a group. The diversity of the answers demonstrates the differences in the learners' depth of understanding.

\section{ASSESSMENT}

A validated student satisfaction survey on the use of online education was adapted to assess satisfaction with the pre-class videos and the class-time Lams case discussion. ${ }^{7}$ The survey consisted of five questions about the student's perceptions of the usefulness and satisfaction with the activity, preference over traditional didactics and desire to expand the use of the activity in the future. Students responded using a four-point Likert scale (1, strongly agree; 2 , agree; 3 , disagree; 4, strongly disagree). Separate surveys were used for the pre-class videos and the class-time lams case discussion. 


\section{Case \#1 - 57 yo with bleeding}

Instructions: Read the case and answer the questions.

Question 1: (Required)

57 year old G0 presents to clinic with a 2 month history of vaginal bleeding. She has been postmenopausal for 4 years. Medical history significant for hypertension, type 2 diabetes and obesity with a BMI of 45 . No surgical history. No gynecological history, but has not seen a gynecologist for 5 years.

\section{What is your differential diagnosis?}

Answer:

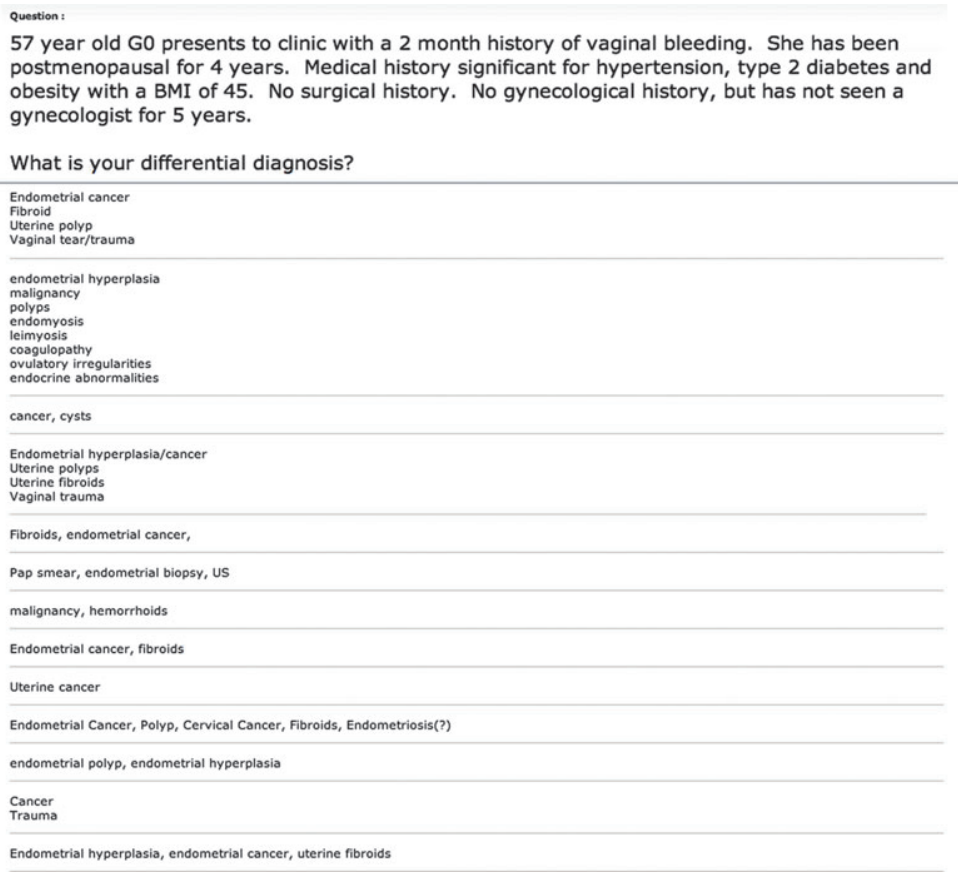

Figure 1. Example of Case-Based Active Learning Session using the Learning Activity Management System (LAMS). The first picture is the screen that the student initially sees on their individual laptop, where each student enters a short-question response. The second picture is the subsequent screen that demonstrates the anonymous responses of their peers
In addition to the satisfaction surveys, students also evaluated the class-time lams case discussion with a general lecture assessment survey given for all clerkship didactic sessions. Evaluations for the gynaecologic oncology sessions prior to implementation of the flipped classroom curriculum were compared with the evaluations of the class-time Lams case discussion.

Aggregate student performance on the gynaecologic reports the data as the percent difference between national and institution scores. The four sessions that corresponded to the previous academic year were compared to the four sessions of data collection of this study. Comparisons were performed using Student's $t$-tests. Results were considered statistically significant if the p-value was less than or equal to 0.05 .

Funding for this curricular innovation was obtained from a University of Michigan Center for Research on Learning and Teaching Investigating Student Learning Grant. An IRB exemption was granted for this project.

\section{RESULTS}

From February to July 2013, 89 third year medical students rotated through the obstetrics and gynaecology clerkship. of these students, $71(80 \%)$ viewed the videos prior to the session and $84(94 \%)$ attended the Lams case discussion. The response rates for the student satisfaction surveys on the videos and class-time Lams case discussions were 85 per cent and 90 per cent, respectively, and student satisfaction was high for both components (Table 1). There were few extremes in the distribution of the responses, with only two of the 76 responses disagreeing with the statement that they supported the expansion of Lams casebased learning. There were many positive student comments about both the pre-class videos and the class-time tams case discussion (Table 2).

There were similarly high satisfaction responses on the general lecture assessment survey after implementation of the flipped classroom curricula (Table 3). There was a statistiresponses to the questions 'the presenter encouraged and provided opportunities for cally significant improvement in
There were positive student comments about the pre- class videos and the class- time LAMS case discussion
National Board of Medical

Examiners (NBME) Obstetrics and Gynaecology Subject students at the completion of their clerkship, was examined before and after implementation of the flipped classroom curriculum. The NBME content area item analysis report provides data on how the students at our institution performed on the gynaecologic oncology questions compared to national scores, and
Examination, required of all 
We were able

to decrease

the amount of

required didactic

time for the

gynaecologic

oncology

content

Table 1. Third-year medical student satisfaction with pre-class videos and class-time lams cases, obstetrics and gynaecology clerkship

Question

This activity is useful prepara-

tion for the clerkship exam

I support expanding the use of this in the future

This activity was preferable to the traditional lecture format

I was satisfied with this activity $3.31 \pm 0.65$

Overall I would rate this activity $3.44 \pm 0.63$ as positive

Survey questions used a four-point Likert scale (1, strongly disagree; 2 , disagree; 3 , agree; 4, strongly agree). Data presented: means \pm standard deviations.

\section{Table 2. Third-year medical student comments about the pre-class videos and class-time Lams cases, obstetrics and gynaecology clerkship}

Pre-class videos

Under 10 minutes is a perfect goal for didactics on certain topics. I loved how the videos distilled what is normally complex information into a clean list of salient points

The cervical dysplasia and the endometrial hyperplasia videos were really memorable with the drawings

Loved the endometrial hyperplasia drawings

The drawings were excellent

The length of the videos was ideal. Easy to listen to. Would like more for other topics!

Thank you for all of your effort, this is a phenomenally better learning experience than normal PowERPINT presentation
Class-time Lams cases

Useful for getting students to reason through cases using knowledge of pathophysiology and general medical knowledge rather than rote memorisation

I really like this format of teaching. Questions addressed without fear of embarrassment at wrong answers

I strongly advocate for this method of lecturing

Definitely some of the best teaching we've had all year

Thank you! This was so helpful to really think about these issues, commit to an answer, and write it down, see how our peers are thinking about these issues, and discuss treatment decisions making

Good practice for creating differentials

practical significance between the means. As suggested by Isaac and Michael, an effect size greater than 0.33 distinguishes differences of practical significance. ${ }^{8}$ There was no significant difference in aggregate student performance on the gynaecologic oncology questions of the NBME Obstetrics and Gynecology Subject Examination. No significant difference was indicated between our institution and the national performance ( 8.3 versus $8.4 \%, p=0.99)$.

\section{DISCUSSION}

Our successful implementation of the flipped classroom curriculum for the gynaecologic oncology topics successfully demonstrates a promising platform for making more efficient use of our students' time, and for increasing their satisfaction with the necessary didactic learning of the clerkship. We were able to decrease the amount of required didactic time for the gynaecologic oncology content from 3 hours to 1 hour, without detrimentally affecting student performance on the NBME exam.

As medical educators ponder the use of the flipped classroom curriculum, we offer some practical considerations that contributed to our successful implementation. We found that students appreciated the short pre-class videos that contained narrated animations. Often educators are tempted to simply narrate their pre-existing didactic lectures; however, Mayer's Cognitive Theory of Multimedia Learning states that people learn better with a combination of animation with narration and text, ${ }^{9}$ and the student comments reflect their positive experiences with these types of pre-class videos.

During the class-time activity, faculty members were able to use students' responses to guide classroom discussion, allowing for more individualised and learner-specific teaching. By focusing on the learners, and their responses, the amount of content that was covered was variable depending on the robustness of the discussion. One 


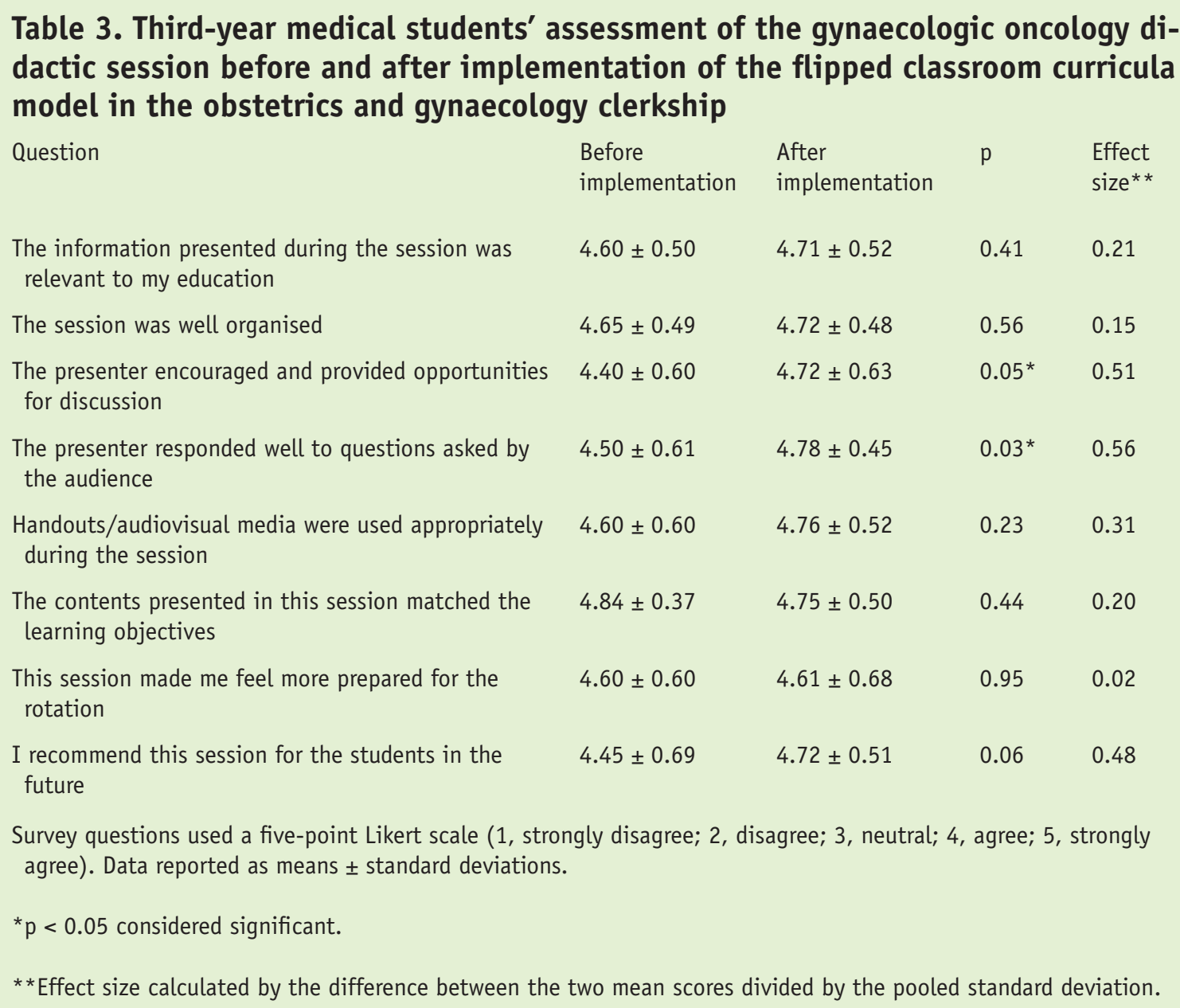

change that we implemented to enhance learning was to give the students a summary of the key points, and the 'correct answers' to the case management decisions at the completion of the class-time lams cases. Because this was a case-based active learning session, faculty members only needed content expertise, and therefore required minimal pre-class preparation.

There were minimal costs to the implementation of the curriculum. The Lams program was a facile platform for use during class, with minimal technical difficulties encountered during implementation. Our IT support was helpful for the initial creation of the videos and the Lams cases; however, once the curriculum was developed and implemented, additional support has not been necessary. Once the Lams cases were created they could be re-used each clerkship period, with minimal additional work required.

Students have advocated for this method of teaching to be expanded to other parts of their curriculum, and we have expanded the use of the flipped classroom, using the Lams case discussions, to the general surgery and the pulmonary sequences at our institution. Future areas of investigation will examine faculty members' satisfaction with this method of teaching, and whether there is a change in student performance after wider implementation of the flipped classroom model.

The teaching of clinical reasoning is a key component of medical education, and our findings illustrate the great potential for using technology to facilitate the coached discussion of cases. The learning of clinical medicine has been described as enhanced when errors in judgment and reasoning are immediately pointed out and discussed. ${ }^{10}$ Our implementation of the flipped classroom curriculum, with the use of the LaMs platform for case-based active learning, enabled class time to be used for this exact type of learning, with high student satisfaction with this modality of teaching. This use of technology to facilitate coached discussion of patient care cases is an example of the transformative power of the flipped classroom curricular model.

\section{REFERENCES}

1. Thompson C. How Khan Academy is changing the rules of education. Wired Posted 15 July 2011. Available at http://www.wired. com/magazine/2011/07/ff_khan/. Accessed on 26 March 2014.

2. Courch CH, Mazur E. Peer instruction: Ten years of experience
Faculty members were able to use students' responses to guide classroom discussion 


This use of
technology ...
is an example
of the
transformative
power of
the flipped
classroom
curricular model

curricular model and results. Am J Physics 2001;69: 970-977.

3. Prober C, Khan S. Medical Education Reimagined: A Call to Action. Acad Med 2013;88:1407-1410.

4. Tune JD, Sturek M, Basile DP. Flipped classroom model improves graduate student performance in cardiovascular, respiratory and renal physiology. Adv Physiol Educ 2013;37:316-320.

5. Missildine K, Fountain R, Summers $\mathrm{L}$, Gosselin K. Flipping the class room to improve student performance and satisfaction. $J$ Nurs Educ 2013;52:597-599.

6. LessonLAMS. Available at http:// lessonlams.com/lams/cloud/index. do. Accessed on 11 November 2013.

7. Vogt M, Schaffner B, Ribar A, Chavez R. The impact of podcasting on the learning and satisfaction of undergraduate nursing students. Nurse Educ Prac 2010;10:38-42.

8. Isaac S, Michael W. Handbook in Research and Evaluation: $A$
Collection of Principles, Methods, and Strategies Useful in the Planning, Design, and Evaluation of Studies in Education and the Behavioral Sciences. Edn 3. San Diego, CA: EDITS Publication; 1997.

9. Mayer RE. Applying the science of learning: Evidence-based principles for the design of multimedia instruction. Am Psychol 2008;63:760-769.

10. Teaching Kassirer J, Reasoning Clinical. Case Based and Coached. Acad Med 2010;85:1118-1124.

Corresponding author's contact details: Helen Morgan, Department of Obstetrics and Gynecology, University of Michigan Medical School, 1500 E. Medical Center Drive, L4000 Von Voigtlander Women's Hospital, Ann Arbor, MI, 48109, USA. E-mail: hjkang@med.umich.edu

Funding: This material is based upon work supported by the University of Michigan Center for Research on Learning and Teaching's Investigating Student Learning Grant, 2012-13 (\$8000).

\section{Conflict of interest: None.}

Acknowledgements: None.

Ethical approval: Institutional Review Board exemption was included with the University of Michigan Center for Research on Learning and Teaching Investigating Student Learning Grant.

doi: $10.1111 /$ tct.12328 